\title{
An analysis of structural relationship among achievement motive on social participation, purpose in life, and role expectations among community dwelling elderly attending day services
}

Nobuyuki Sano, Makoto Kyougoku

Background: Achievement motive is defined as the intention to achieve one's goals. Achievement motive is assumed to promote clients to choices and actions toward their valuable goal, so it is an important consideration in rehabilitation. Purpose: The purpose of this study is to demonstrate the structural relationship among achievement motive on purpose in life, social participation, and role expectation of community-dwelling elderly people. Methods: Participants were community-dwelling elderly people in day-service centers. A total of 281 participants (male: 127, female: 154) answered the selfadministered questionnaire in cross-sectional research. The questionnaire was comprised of demographic data and scales that evaluated achievement motive, social participation, purpose in life, and role expectation. We studied the structural relationship established by our hypothesized model via a structural equation modeling approach. Results: We checked the standardized path coefficients and the modification indices; the modified model's statistics were a good fit: $\mathrm{CFI}=0.984, \mathrm{TLI}=0.983, \mathrm{RMSEA}=0.050,90 \% \mathrm{Cl}$ $[0.044,0.055]$. Achievement motive had a significantly direct effect on purpose in life (direct effect $=0.445, \mathrm{p}$ value $<0.001$ ), a significantly indirect effect on purpose in life via social participation or role expectation (indirect effect $=0.170, p$ value $<0.001$ ) and a total effect on purpose in life (total effect $=0.615$ ). Discussion: This result suggests that enhancing the intention to achieve one's goals enables participants to feel a spirit of challenge with a purpose and a sense of fulfillment in their daily lives. 
1 An analysis of structural relationship among achievement motive on social participation,

2 purpose in life, and role expectation in community dwelling elderly attending day services

4 Abstract

5 Background: Achievement motive is defined as the intention to achieve one's goals.

6 Achievement motive is assumed to promote clients to choices and actions toward their valuable

7 goal, so it is an important consideration in rehabilitation.

8 Purpose: The purpose of this study is to demonstrate the structural relationship among

9 achievement motive on purpose in life, social participation, and role expectation of community-

10 dwelling elderly people.

11 Methods: Participants were community-dwelling elderly people in day-service centers. A total

12 of 281 participants (male: 127, female: 154) answered the self-administered questionnaire in

13 cross-sectional research. The questionnaire was comprised of demographic data and scales that

14 evaluated achievement motive, social participation, purpose in life, and role expectation. We

15 studied the structural relationship established by our hypothesized model via a structural

16 equation modeling approach. 
17 Results: We checked the standardized path coefficients and the modification indices; the

18 modified model's statistics were a good fit: $\mathrm{CFI}=0.984, \mathrm{TLI}=0.983, \mathrm{RMSEA}=0.050,90 \% \mathrm{CI}$

$19[0.044,0.055]$. Achievement motive had a significantly direct effect on purpose in life (direct

20 effect $=0.445, \mathrm{p}$ value $<0.001)$, a significantly indirect effect on purpose in life via social

21 participation or role expectation (indirect effect $=0.170, \mathrm{p}$ value $<0.001$ ) and a total effect on

22 purpose in life (total effect $=0.615)$.

23 Discussion: This result suggests that enhancing the intention to achieve one's goals enables

24 participants to feel a spirit of challenge with a purpose and a sense of fulfillment in their daily

25 lives.

27 Authors:

28 Nobuyuki Sano $^{1}$ Makoto Kyougoku ${ }^{2}$

29 Affiliations:

$30{ }^{1}$ Doctor Course, Graduate School of Health Sciences, Kibi International University, Okayama,

31 Japan

$32{ }^{2}$ Department of Occupational Therapy, School of Health Sciences, Kibi International University, 


\section{Okayama, Japan}

35 Corresponding author:

36 Nobuyuki Sano

37 Address: 8, Iga-machi, Takahashi city, Okayama, Japan

38 Phone number: 090-8717-1836

39 Email address: sanokichi09094@gmail.com. 


\section{Introduction}

41 Achievement motive was proposed as a concept of psychogenic needs by Murray

42 (Murray 1938) and, was defined as "a recurrent need to improve one's past performance" by

43 McClelland (McClelland 1987). Achievement motive has been associated with various concepts

44 such as intrinsic motivation, achievement goal, and self-efficacy (Bandura 1977; Nicholls 1984;

45 Ryan \& Deci 2000). These concepts share the idea that individual motives are required to

46 achieve goals although they differ with respect to theoretical background and the phenomena that

47 researchers try to understand; for example, intrinsic motivation assumes that all people are

48 inclined to participate in independent and active learning (Ryan \& Deci 2000), and self-efficacy

49 additionally involves the implicit assumption that all people have a desire to be competent

50 (Bandura 1977). Thus, these terms have a common meaning with regard to achieving the same

51 goal.

In rehabilitation, achievement motive is a significant concept concerning the

53 assessment and intervention of clients (Lampton, Lambert \& Yost 1993; Resnick et al. 2002;

54 Spivack et al. 1982; Vanetzian 1997). The World Health Organization (WHO) defined the

55 rehabilitation of people with disabilities as "a process aimed at enabling them to reach and 
56 maintain their optimal physical, sensory, intellectual, psychological, and social functional levels.

57 Rehabilitation provides disabled people with the tools they need to attain independence and self-

58 determination" (WHO 2015). To enable them to attain independence and self-determination, it is

59 important to assesse and treat the unique experiences, goals, and values of each person in the

60 person-centered therapy (Cloninger \& Cloninger 2011). In other words, rehabilitation assumes to

61 motivate and coach clients to be able to make self-directed choices for their own well-being and

62 take initiative for achieving their own autonomy. Therefore, achievement motive focuses on the

63 strength of the needs to improve based on experiences, goals, and values of clients. emphasized that rehabilitation with an "Activity" and "Participation" framework is important,

66 especially for elderly people, because the conventional rehabilitation for elderly people has been

67 insufficient in improving the general functioning involved with activity and participation

68 (Tsuruta 2015). Activity and participation is the valuable; however, they should be task- and

69 action-oriented that is executed originally or attempted to be execute anew. In support of the

70 concept of activity and participation, it is necessary to enable elderly people to live with a

71 purpose in life ("Ikigai" in Japanese) and fulfill role expectations in their lives (Tsuruta 2015). 
72 Purpose in life refers to the tendency to derive meaning from life's experiences and possess a

73 sense of intentionality and goal directedness that guides behavior (Boyle et al. 2009; Boyle,

74 Buchman \& Bennett 2010). Previous studies of purpose in life have been shown to be associated

75 with psychological outcomes such as well-being and happiness (Ryff et al. 2006; Ryff \& Keyes

76 1995; Samman 2007). Also, the study for middle-aged and elderly people revealed that purpose

77 in life positively affected social participation over a 6-month period (Imai 2013). Social

78 participation is defined in terms of the consequences of activities in the social environment

79 (Bukov, Maas \& Lampert 2002). Furthermore, purpose in life involves role expectation, which is

80 defined as an understanding of one's contribution to society and others (Demura \& Sato 2006).

81 Moreover, the study on community-dwelling elderly people showed that achievement motive

82 affected social participation and health-related quality of life (HRQOL, comprising of vitality,

83 role physical, role emotional, and general health perception) positively(Sano, Kyougoku \&

84 Teraoka 2015). Achievement motive is assumed to promote clients' choices and actions toward

85 their valuable goal. However, the effect of achievement motive on purpose in life, role

86 expectation, and social participation is unclear. 
88 social participation, purpose in life, and role expectation for elderly persons. In addition, we

89 hypothesized that social participation and role expectation promoted by achievement motive

90 have an enhancing effect on purpose in life. Therefore, we created a hypothesized model

91 demonstrating that achievement motive has a positive effect on purpose in life, role expectation,

92 and social participation and that social participation and role expectation have a positive effect

93 on purpose in life (Fig. 1).

94 The purpose of this study was to demonstrate the structural relationship among

95 achievement motive on purpose in life, social participation, and role expectation among

96 community-dwelling elderly people. The structural relationship is a snapshot of a point in time

97 and the observed findings suggest an influence on the variables (Teraoka \& Kyougoku 2015).

98 Methods

99 Ethics statement

100 This study employed a cross-sectional design. It was conducted in accordance with the

101 Declaration of Helsinki and was approved by the Ethics Committee of the Kibi International

102 University (No. 13-34). In addition, we gained approval from the facility directors of the

103 institutions that cooperated in this study. We explained to participants that they could freely 
104 decide whether to participate in the study and could refuse to answer the questionnaire during

105 this study. We completely protected the privacy of personal information. Furthermore, we

106 obtained written informed consent from all participants. Participants put questionnaires in a box

107 or handed them to staff.

108

109 Participants

110 Participants were community-dwelling elderly people in day-service centers. As the

111 exclusion criteria, we excluded people who had been diagnosed with mental disorders such as

112 schizophrenia and dementia, those who demonstrated clinical decline of cognitive function, and

113 those who could not read or write the questionnaire forms.

\section{Questionnaires}

116 1) Demographic information

117 Demographic data such as gender, age, the name of the primary illness or disease,

118 nursing care level (needing care: 1-5, needing support: 1-2 or nothing), the number of

119 housemates, activities outside the home and hobbies, family structure, and subjective economic 
120 condition were obtained. The respective number of outside-the-home activities and hobbies were

121 determined as follows: "How many times a week do you usually go outside your home?" and

122 "How many hobbies do you have that continue to give you pleasure?" The subjective economic

123 condition ranged from 1 to $4(1=\mathrm{I}$ am economically stable and I don't have to worry and $4=\mathrm{I}$

124 am poor and very nervous about my financial future) (Mizota et al. 2009).

125

126 2) SAMR (Sano \& Kyougoku 2015; Sano, Kyougoku \& Yabuwaki 2014)

127 We selected SAMR comprising 10 items to evaluate the state of achievement motive

128 of clients and assumed in oblique 2-factor models: a) Self-mastery-derived (six items), b)

129 Means/process-oriented-derived (four items). Each item in SAMR had a 7-point Likert scale

130 ranging from 1 (strongly disagree) to 7 (strongly agree). The following is an example of an item:

131 "I think that I can overcome any difficulty to achieve my goal." (Appendix). The standardization

132 score calculated depending on a total score, and if the achievement motive is strong then the

133 standardization score will be high.

135 3) Self-Completed Occupational Index (SOPI) (Imai \& Saito 2010; Imai \& Saito 2011) 
137 clients and assumed in oblique 3-factor models: a) Leisure, b) Productivity, c) Self-care (each

138 with three items). Each item in SOPI had a 5-point Likert scale ranging from 1 (I hardly have

139 been satisfied) to 5 (I have been very satisfied). Summary score was calculated the following

140 equation; (total score of 9 items -9 ) / $36 \times 100$. The following in an example of an item: "Have

141 you been able to perform important leisure activities in the past month?" SOPI was accepted for

142 validity (concurrent) and reliability (internal consistency). If the quality of social participation is

143 high then the summary score of SOPI will also be high.

145 4) K-1 Scale for the Feeling that Life Is Worth Living among the Aged (K-1 Scale) (Kondo 146 2007) assumed in oblique 4-factor models: a) Self-realization and will (six items), b) Sense of life example of an item: "I feel something to realize my accomplishment." We reverse-scored item 2, 
1524,9 , and 12, phrased such that an agreement with the item represented a low level of purpose in

153 life. K-1 Scale was accepted for validity (concurrent, factorial) and reliability (test-retest,

154 internal consistency). If the quality of purpose in life is high, the total score of K-1 Scale will

155 also be high.

156

157 5) Role expectation

158 We evaluated role expectation in a multiple-choice form. We provided 11 items for

159 reference to a role checklist: volunteer, caregiver, housework, friend, family member, religionist,

160 hobbyist or amateur, participant in an organization, student, worker, and other (Kielhofner 2007).

161 Participants selected the roles that were applicable to them. In the analysis, we counted the total

162 number of chosen roles and aggregated choices of each role.

163

\section{Statistical methods}

166 (http://www-01.ibm.com/software/jp/analytics/spss/products/statistics/). Item validity was

167 conducted using Exametrika Version 5.3 (http://antlers.rd.dnc.ac.jp/ shojima/exmk/index.htm). 
168 Correlation between SAMR, SOPI, K-1 Scale and role expectation were conducted using

169 HAD12 (http://norimune.net/had). Tests of structural validity and structural relationship were

170 conducted using Mplus v7.2 (http://www.statmodel.com).

171

172 1) Descriptive statistics and test of normality

We performed simple descriptive statistics including means and standard deviation

174 (SD) and calculated the Kolmogorov-Smirnov test, skewness, and kurtosis.

175

176

2) Items validity

177 We calculated the mean information content (entropy) and the total polyserial correlation coefficient (PCC) for all items of SAMR, SOPI, and K-1 Scale. A PCC value of $>0.2$ was the standard item validity (Toyoda 2002).

180

181

\section{3) Structural validity}

182 We analyzed the factor structure of SAMR, SOPI, and K-1 Scale using confirmatory

183 factor analysis (CFA) by a structural equation modeling (SEM) approach (Muthén 1983) for the 
184 participation of this study. The factor structure of each scale was examined using the same factor

185 structure as previous studies. We used the Maximum Likelihood with Robust standard error

186 (MLR) with missing data for SAMR and SOPI and the modified weighted least squares method

187 (WLSMV) with missing data for K-1 Scale. We referred to several fit indices: CFI, Tucker

188 Lewis Index (TLI), and RMSEA with 90\% confidence interval (CI). A CFI and TLI value of

$189>0.9$ was the best model fit. For RMSEA, values $\leq 0.05$ indicate a close fit, those of $\leq 0.08$

190 indicate a reasonable fit, and those of $\geq 0.1$ indicate a poor fit (MacCallum, Browne \& Sugawara

191 1996).

192

193 4) Correlation between SAMR, SOPI, K-1 Scale, and role expectation

194

We calculated polychoric correlation, polyserial correlation or spearman correlation for

195 subscale score, total scale score, and summary score of SAMR, SOPI, K-1 scale, and role

196 expectation (total number of role item, each role item). Values of $>0.2$ and $<0.4$ indicate weak

197 correlation, those of $>0.4$ and $<0.7$ indicate moderate correlation, and those of $>0.7$ and $<0.9$

198 indicate a strong correlation.

199 


\section{5) Structural relationship}

(MIMIC) by a SEM approach. MIMIC is the model to verify a hypothesis that some observation

in life) fit our data. We used the WLSMV with missing data for our analysis and referred to

several fit indices: CFI, TLI, RMSEA, 90\% CI. The standard of the best model fit was the same with $90 \%$ CI.

\section{Results}

\section{1) Participant characteristics}

215 this study. A total number of 281 participants answered the questionnaire (valid response rate: 
216 92.4\%); 127 (45.2\%) were men and 154 (54.8\%) were women, and mean age was $77.1 \pm 8.7$

217 years. Details of the sample characteristics are described in Table 1.

218

219 2) Descriptive statistics and test of normality

Table 2 indicates descriptive statistics and normality tests of the three scales (SAMR,

221

SOPI, and K-1). In a test of normality of each scales, total score of SAMR is 0.003 (skewness = -

222

0.821 , kurtosis $=1.560)$, summary score of SOPI is 0.069 (skewness $=0.100$, kurtosis $=-0.671)$,

223

total score of K-1 Scale is 0.000 (skewness $=-0.546$, kurtosis $=-0.514$ ). Although the other

variables had not an extreme deviation from the mean and SD, the items of SAMR and K-1 were

225 needed attention in skewness and kurtosis.

\section{3) Items validity}

All items for SAMR, SOPI, and K-1 Scale were accepted and the value satisfied the standard of PCC (Table 2).

230 
233 structure with previous studies. Fit indices of SAMR were CFI $=0.955$, TLI $=0.941$, RMSEA $=$

$2340.061,90 \%$ CI $[0.040,0.081]$, and factorial correlation between Self-mastery-derived and

235 Means/process-oriented-derived was 0.768 (Fig. 2). Fit indices of SOPI were CFI $=0.982$, TLI $=$

$2360.976, \mathrm{RMSEA}=0.058,90 \% \mathrm{CI}[0.034,0.082]$, and factorial correlation between three factors

237 was 0.731 (Leisure and Productivity), 0.598 (Leisure and Self-care) and 0.625 (Productivity and

238 Self-care) (Fig. 3). Fit indices of K-1 Scale were CFI $=0.944$, TLI $=0.932$, RMSEA $=0.078$,

$23990 \% \mathrm{CI}[0.066,0.089]$ and factorial correlation between four factors was 0.670 (Self-realization

240 and will and Sense of life fulfillment), 0.822 (Self-realization and will and Will to live), 0.813

241 (Self-realization and will and Sense of existence), 0.583 (Sense of life fulfillment and Will to

242 live), 0.558 (Sense of life fulfillment and Sense of existence), and 0.804 (Will to live and Sense

243 of existence) (Fig. 4). Although SAMR and K-1 Scale were not sufficient to test for normality,

244 we comprehensively decided that all scales were available for examination of correlation

245 between this study variable and structural relationship. 
249 descriptive contents of other were unspecified. Positive correlation was accepted between most

250 of the subscale score, summary score, and total scale score of SAMR, SOPI, and K-1 scale

251 (Table 3). Of the total number of role items, the roles of Friend, Hobbyist or Amateur, and

252 Participant in an Organization were a positive correlation with SAMR, SOPI, and K-1 scale 253 (Table 4).

moderately correlated with the subscale score of Self-realization and will, Sense of existence, and total scale scores of K-1 Scale $(0.404-0.542)$. The roles of volunteer, friend, hobbyist or amateur, participant in an organization, and worker were moderately correlated with the subscale score of K-1 Scale or a total scale score of K-1 Scale (0.403-0.528).

\section{6) Structural relationship}


264 Self-mastery-derived was beyond 1.0 (1.099), and the hypothesized model was suspected to

265 involve model misspecification. The correlation of two factors of SAMR was very strong;

266 therefore, a problem of linear dependence between these two factors or these items may occur,

267 similar to that in previous studies (Sano 2014). To revise the model by equality constraints

268 associated with Self-mastery-derived, we restricted the standardized path coefficients of Self-

269 mastery-derived on the factor's items and achievement motive on two factors of SAMR were to

270 1. As a result, the modified model was good fit statistics: $\mathrm{CFI}=0.984, \mathrm{TLI}=0.983$, RMSEA $=$

$2710.050,90 \%$ CI $[0.044,0.055]$ and did not involve standardized path coefficients beyond 1.0 (Fig.

272 6). With respect to the standardized path coefficients in the modified model, achievement motive

$273($ direct effect $=0.445, \mathrm{p}$ value $=0.000)$, social participation $($ direct effect $=0.161, \mathrm{p}$ value $=$

2740.015 ), and role expectation (direct effect $=0.224, \mathrm{p}$ value $=0.000$ ) had a significant positive

275 impact on purpose in life; achievement motive (direct effect $=0.499, \mathrm{p}$ value $=0.000$ ) had a

276 significant positive impact on social participation; and achievement motive $($ direct effect $=0.400$,

$277 \mathrm{p}$ value $=0.000)$ had a significant positive impact on role expectation. Achievement motive

278 [indirect effect $=0.080, \mathrm{p}$ value $=0.018,95 \% \mathrm{CI}(0.014,0.147)]$ had a significant positive effect

279 on purpose in life via social participation, and achievement motive [indirect effect $=0.089, \mathrm{p}$ 
280 value $=0.000,95 \%$ CI $(0.043,0.136)]$ had a significant positive effect on purpose in life via role

281 expectation. The sum of indirect effect was standardized path coefficients $=0.170, \mathrm{p}$ value $=$

$2820.000,95 \%$ CI $[0.079,0.260]$. The total effect of the achievement motive on purpose in life was

283 standardized path coefficients $=0.615($ direct effect $=0.445+$ indirect effect $=0.170)$.

284

285 Discussion

The purpose of this study was to demonstrate the structural relationship among

287 achievement motive on purpose in life, social participation, and role expectation of community-

288 dwelling elderly people. We were able to show statistical evidence according to our hypothesis.

289 Moreover, item validity and structural validity of SAMR, SOPI, and K-1 Scale were acceptable

290 in this study. That is, these assessments function well as tools for quantification.

291 In the test of a structural relationship based on our hypotheses, it was demonstrated

292 that achievement motive had a positive impact on purpose in life, social participation, and role

293 expectation. Moreover, social participation and role expectation had a positive impact on purpose

294 in life. We proved the strong effect of achievement motive on outcome indices of elderly persons.

295 In addition, we confirmed the significantly indirect effects of achievement motive on purpose in 
296 life via social participation or role expectation. We could expect that purpose in life became

297 enhanced through improvements of social participation or role expectation by achievement

298 motive. These results suggest that enhancing the intention to achieve one's goals allows

299 participants to feel a spirit of challenge with a purpose and a sense of fulfillment in daily living.

300 At the same time, recognizing engagement in important activities for oneself and the role of

301 oneself in society also helps participants feel capable of being helpful to others. significantly high. The result indicated that achievement motive had greater effects on the support-related purpose in life for elderly persons than on social participation and role expectation. In previous studies, purpose in life has been associated with well-being and life satisfaction (Bronk et al. 2009; Ryff 1989; Ryff \& Keyes 1995), and has had an effect on restraining mortality risk, anxiety, and stress (Boyle et al. 2009; Ishida 2012). Also, purpose in life is future-orientated and goal-orientated (Bronk et al. 2009), and involves the individual's intention to achieve something (Demura \& Sato 2006; Nomura 2005); therefore, enhancing

310 purpose in life may be the goal for the rehabilitation of elderly persons. Thus, we considered the

311 importance of pursuing the achievement of individual goals and ways of life. Establishing and 
312 sharing goals between client and therapist based on consultation about ideals and meaning in life

313 is very important in rehabilitation.

315 participation, and role expectation because these significant correlations were accepted among

316 SAMR, SOPI, K-1 Scale, and the total number of role items. In particular, Self-mastery-derived

317 was closely related to purpose in life due to moderate correlation with the subscale score and

318 total scale score of K-1 Scale. Accordingly, we suggest that it is important to support clients in

319 rehabilitation by enhancing their own abilities and intelligence through training, feedback, etc.

321 achievement motive, social participation, and purpose in life were not associated with the role in

322 the home (Caregiver, Housework, and Family member). On the other hand, these concepts were

323 positively associated with most roles related to society (friend, hobbyist or amateur, participant

324 in an organization, and worker). Therefore, we suspect that roles within the home do not have

325 much of an effect on the health care of community-dwelling elderly people. In contrast, we

326 expect that it is more effective to support community-dwelling elderly people in roles related to

327 their relationship with society. 
329 Contribution and limitation This study proved the structural relationship among achievement motive on purpose in

331 life, social participation, and role expectation of community-dwelling elderly people. We believe

332 that this study reveals the far-reaching effects of achievement motive. Although achievement

333 motive has not been sufficiently studied, it is considered an important element in rehabilitation.

334 (Resnick 1996). Therapists who perform rehabilitation may be able to share and collaborate with

335 others in attaining the goal of helping clients from this new standpoint of achievement motive.

336 This study has a few limitations on the study design. First, this study utilized data

337 sampling and research for the participants restricted to day-service centers in specified areas.

338 Second, this study used a self-reported questionnaire to collect data and could examine only

339 subjective effects but could not examine effects by objective data indices. We hope to continue

340 this study while considering these limitations. For example, elucidating the structural

341 relationship between genders and among ages would be useful in future studies. 

who supported us.

\section{References}

\section{Uncategorized References}

Bandura A (1977) Self-efficacy: toward a unifying theory of behavioral change. Psychological Review 84:191-215.

Boyle PA, Barnes LL, Buchman AS, and Bennett DA (2009) Purpose in life is associated with mortality among community-dwelling older persons. Psychosomatic Medicine 71:574579.

Boyle PA, Buchman AS, and Bennett DA (2010) Purpose in life is associated with a reduced risk of incident disability among community-dwelling older persons. American Journal of Geriatric Psychiatry 18:1093-1102.

Bronk KC, Hill PL, Lapsley DK, Talib N, and Finch H (2009) Purpose, hope, and life satisfaction in three age groups. Journal of Positive Psychology 4:500-510.

Bukov A, Maas I, and Lampert T (2002) Social participation in very old age: cross-sectional and longitudinal findings from BASE. Berlin Aging Study. Journals of Gerontology Series B: Psychological Sciences and Social Sciences 57:P510-517.

Cloninger CR, and Cloninger KM (2011) Person-centered Therapeutics. International Journal of Person Centered Medicine 1:43-52.

Demura S, and Sato S (2006) Quality of Life (QOL) Assessment for Japanese Elderly : the course of QOL studies and assessments of health-related and subjective QOL. JapanJPhys Educ HlthSport Sci 51:103-115.

Imai T (2013) Effects of occupational participation on the concept of "IKIGAI" : A six-month follow-up survey for healthy middle-aged and elderly in Japan. The Journal of Japanese 
370

371

372

373

374

375

376

377

378

379

380

381

382

383

384

385

386

387

388

389

390

391

392

393

394

395

396

397

398

399

400

401

Occupational Therapy Association 32:142-150.

Imai T, and Saito S (2010) Measuring the quality of participation in activities in everyday life : Developing the Self-completed Occupational Performance Index (SOPI). The Journal of Japanese Occupational Therapy Association 29:317-325.

Imai T, and Saito S (2011) Effects of participating in meaningful occupation on HR-QOL : A six-month follow-up survey on healthy elderly and middle-aged adults in Japan. The Journal of Japanese Occupational Therapy Association 30:42-51.

Ishida R (2012) Reducing anxiety in stutterers through the association between "purpose in life/Ikigai" and emotions. Glob J Health Sci 4:120-124.

Kielhofner G (2007) Model of Human Occupation: Theory and Application 4TH Edition. Lippincott Williams \& Wilkins Place

Kondo T (2007) IKIGAI measuring: what is IKIGAI? Nakanishiya-Syuppan Place

Kosugi K, and Shimizu H (2014) Introduction to structural equation modeling in Mplus and R. Kitaohji Shobo Place

Lampton CC, Lambert ME, and Yost R (1993) The effects of psychological factors in sports medicine rehabilitation adherence. Journal of Sports Medicine and Physical Finess 33:292-299.

MacCallum R, Browne M, and Sugawara H (1996) Power analysis and determination of sample size for covariance structure modeling. Psychological Methods 1:130-149.

McClelland DC (1987) Human motivation. Cambridge University Press. Place

Mizota K, Murata S, Otao H, Kai Y, Murata J, Ikeda N, Tominaga K, and Oyama M (2009) Relationship between subjective economic conditions and QOL in elderly female residents of the community. West Kyushu Journal of Rehabilitation Sciences 2:1-6.

Murray HA (1938) Explorations in personality. Oxford Univ. Press. Place

Muthén B (1983) Latent variable structural equation modeling with categorical data. Journal of Econometrics 22:43-65.

Nicholls JG (1984) Achievement motivation: conceptions of ability, subjective experience, task choice, and performance. Psychological Review 91:328-346.

Nomura C (2005) Worth Living of Elderly: A Concept Analysis. Journal of Japan Academy of Nursing Science 25:61-66.

Resnick B (1996) Motivation in geriatric rehabilitation. Image - the Journal of Nursing Scholarship 28:41-45. 
402 Resnick B, Magaziner J, Orwig D, and Zimmerman S (2002) Evaluating the components of the

403

404

405

406

407

408

409

410

411

412

413

414

415

416

417

418

419

420

421

422

423

424

425

426

427

428

429

430

431

432

433

Exercise Plus Program: rationale, theory and implementation. Health Education Research 17:648-658.

Ryan RM, and Deci EL (2000) Intrinsic and Extrinsic Motivations: Classic Definitions and New Directions. Contemporary Educational Psychology 25:54-67.

Ryff C (1989) Happiness is everything, or is it? Explorations on the meaning of psychological well-being. Journal of Personality and Social Psychology 57:1069-1081.

Ryff CD, Dienberg LG, Urry HL, Muller D, Rosenkranz MA, Friedman EM, Davidson RJ, and Singer B (2006) Psychological well-being and ill-being: do they have distinct or mirrored biological correlates? Psychotherapy and Psychosomatics 75:85-95.

Ryff CD, and Keyes CL (1995) The structure of psychological well-being revisited. Journal of Personality and Social Psychology 69:719-727.

Samman E (2007) Psychological and Subjective Well-being: A Proposal for Internationally Comparable Indicators. Oxford Development Studies 35:459-486.

Sano N. 2014. Effect of achievement motive for Community-Dwelling Elderly Persons on social participation and HR-QOL. Program of the 56th annual Meeting of The Japanese Association of Educational Psychology: Program of the 56th annual Meeting of The Japanese Association of Educational Psychology. p 720.

Sano N, and Kyougoku M (2015) Examination of structural validity of a Scale for Achievement Motive in Rehabilitation (SAMR) for Community-Dwelling Elderly Persons. Sogo Rihabiriteshon 43:341-347.

Sano N, Kyougoku M, and Teraoka M (2015) Effect of achievement motive for CommunityDwelling Elderly Persons on social participation and HR-QOL. Sogo Rihabiriteshon 43:765-772.

Sano N, Kyougoku M, and Yabuwaki K (2014) Development of a Scale for Achievement Motive in Rehabilitation (SAMR). Sogo Rihabiriteshon 42:667-674.

Spivack G, Siegel J, Sklaver D, Deuschle L, and Garrett L (1982) The long-term patient in the community: life style patterns and treatment implications. Hospital and Community Psychiatry 33:291-295.

Teraoka M, and Kyougoku M (2015) Analysis of structural relationship among the occupational dysfunction on the psychological problem in healthcare workers: a study using structural equation modeling. PeerJ 19:e1389. 
434 Toyoda H (2002) Item response theory -case study- (The constitution method of new $435 \quad$ psychological test). Asakura Shoten Place

436 Tsuruta S (2015) Future directions of the long-term care prevention. Sogo Rihabiriteshon $437 \quad 43: 803-808$.

438 Vanetzian E (1997) Learning readiness for patient teaching in stroke rehabilitation. Journal of $439 \quad$ Advanced Nursing 26:589-594.

440 WHO Health topics Rehabilitation. Available at

441 http://www.who.int/topics/rehabilitation/en/ (accessed 19 September 2015).

442 
1

Hypothesized model

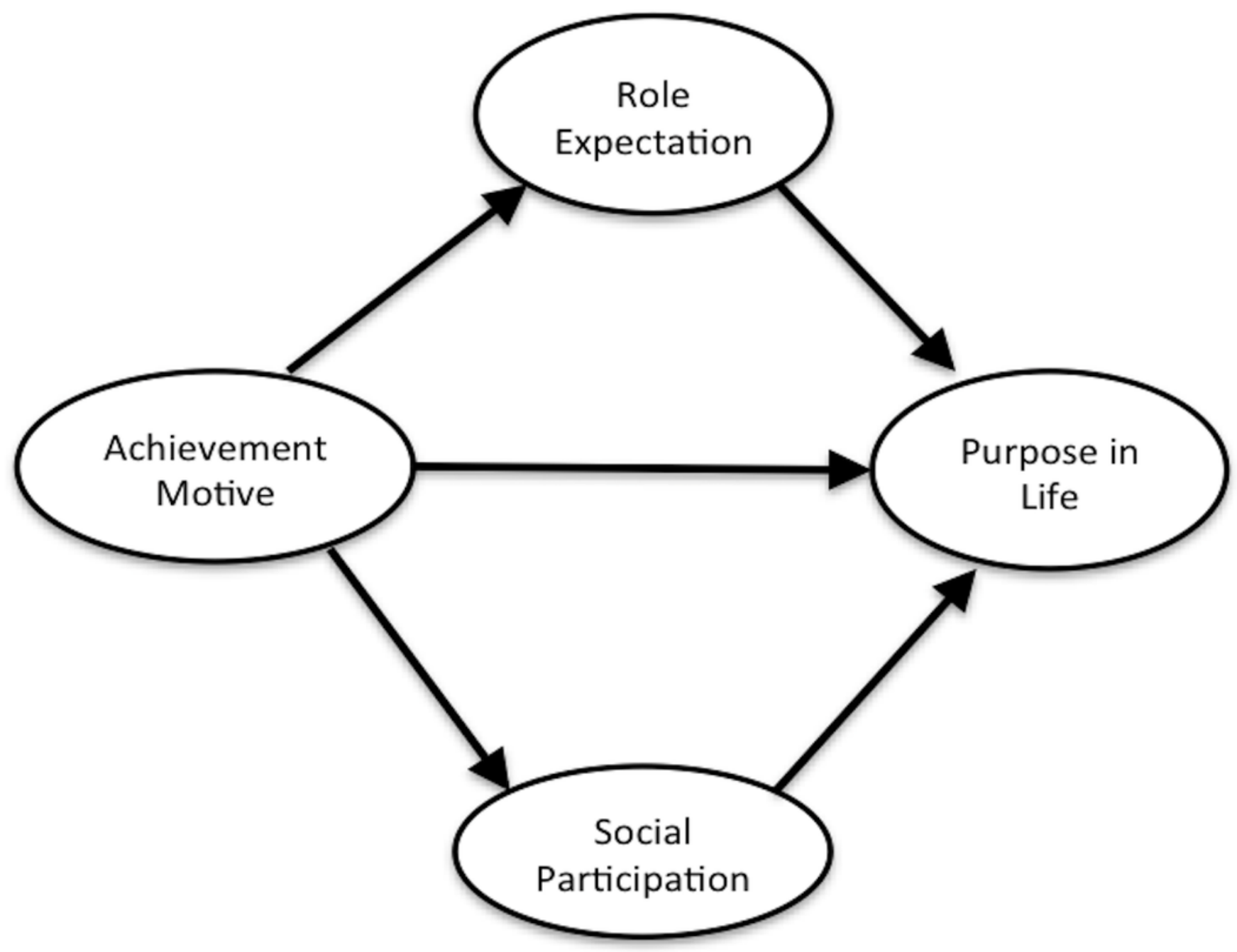




\section{Table $\mathbf{1}$ (on next page)}

Table 1

Participant characteristics 


\begin{tabular}{|c|c|c|c|}
\hline & Class & $n=281$ & $\%$ \\
\hline \multirow[t]{2}{*}{ gender } & male & 127 & $45.2 \%$ \\
\hline & female & 154 & $54.8 \%$ \\
\hline age (mean $\pm S D)$ & $77.1 \pm 8.7$ & & \\
\hline \multirow[t]{5}{*}{ disease } & orthopedic & 111 & $39.5 \%$ \\
\hline & neurological & 108 & $38.4 \%$ \\
\hline & heart & 5 & $1.8 \%$ \\
\hline & others & 29 & $10.3 \%$ \\
\hline & unknown & 28 & $10.0 \%$ \\
\hline \multirow[t]{9}{*}{ care level } & care5 & 0 & $0.0 \%$ \\
\hline & care4 & 8 & $2.8 \%$ \\
\hline & care3 & 23 & $8.2 \%$ \\
\hline & care2 & 74 & $26.3 \%$ \\
\hline & care 1 & 65 & $23.1 \%$ \\
\hline & support2 & 59 & $21.0 \%$ \\
\hline & support1 & 48 & $17.1 \%$ \\
\hline & nothing & 0 & $0.0 \%$ \\
\hline & unknown & 4 & $1.4 \%$ \\
\hline housemate (mean $\pm S D)$ & $1.6 \pm 1.4$ & & \\
\hline going out (mean $\pm S D)$ & $4.0 \pm 3.0$ & & \\
\hline hobby (mean $\pm S D)$ & $1.4 \pm 1.3$ & & \\
\hline \multirow[t]{2}{*}{ spouse } & with & 160 & $56.9 \%$ \\
\hline & without & 121 & $43.1 \%$ \\
\hline \multirow[t]{2}{*}{ grandchildren } & with & 44 & $15.7 \%$ \\
\hline & without & 237 & $84.3 \%$ \\
\hline \multirow[t]{5}{*}{ economic condition } & 1 & 68 & $24.2 \%$ \\
\hline & 2 & 172 & $61.2 \%$ \\
\hline & 3 & 38 & $13.5 \%$ \\
\hline & 4 & 2 & $0.7 \%$ \\
\hline & unknown & 1 & $0.4 \%$ \\
\hline \multirow[t]{2}{*}{ roles (mean $\pm S D$ ) } & $1.5 \pm 1.0$ & & \\
\hline & Volunteer & 9 & $3.2 \%$ \\
\hline
\end{tabular}


1

Care giver

$3 \quad 1.1 \%$

House work

$73 \quad 26.0 \%$

2

Friend

$46 \quad 16.4 \%$

Family member

$207 \quad 73.7 \%$

Religionist

$9 \quad 3.2 \%$

Hobbyist

$42 \quad 14.9 \%$

Organization

$15 \quad 5.3 \%$

Student

$0 \quad 0.0 \%$

Worker

$5 \quad 1.8 \%$

Other

$17 \quad 6.0 \%$


2

CFA of SAMR

$\mathrm{CFI}=0.955, \mathrm{TLI}=0.941, \mathrm{RMSEA}=0.061,90 \% \mathrm{Cl}[0.040,0.081]$. Abbreviations of the four factors are similar to Table 3.

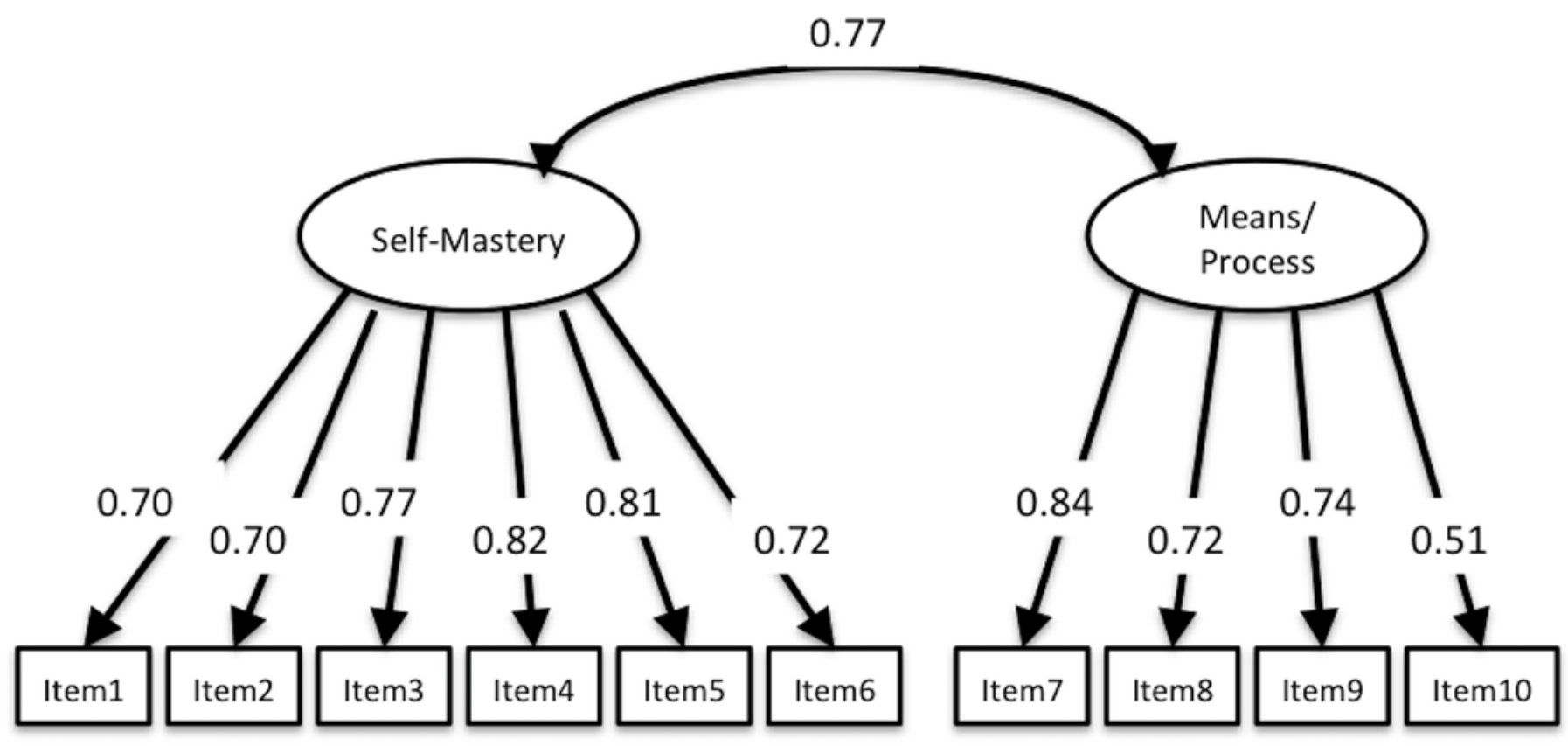




\section{Table 2 (on next page)}

Descriptive statistics, and Items validity

Self-mastery-derived involves Item1-6 of SAMR, Means/process-oriented-derived involves Item7-10 of SAMR. Leisure involves Item1-3 of SOPI, Productivity involves Item4-6 of SOPI, Self-care involves Item7-9 of SOPI. Self-realization and will involves Item1, 3, 5, 6, 14, 15 of K-1 Scale, Sense of life fulfillment involves Item2, 4, 8, 9, 12 of K-1 Scale, Will to live involves Item11, 13 of K-1 Scale, Sense of existence involves Item7, 10, 16 of K-1 Scale. 


\begin{tabular}{|c|c|c|c|c|}
\hline Item & Mean & SD & Entropy & PCC \\
\hline \multicolumn{5}{|l|}{ SAMR } \\
\hline Item1 & 5. 129 & 1. 390 & 2.363 & 0.744 \\
\hline Item2 & 5. 089 & 1. 332 & 2.290 & 0.697 \\
\hline Item3 & 5. 139 & 1. 419 & 2.406 & 0.748 \\
\hline Item4 & 4. 723 & 1. 442 & 2.468 & 0.825 \\
\hline Item5 & 5. 299 & 1. 370 & 2.324 & 0.819 \\
\hline Item6 & 4. 750 & 1. 389 & 2.407 & 0.748 \\
\hline Item7 & 5. 786 & 1. 277 & 2.109 & 0.756 \\
\hline Item8 & 5. 505 & 1. 300 & 2.248 & 0.694 \\
\hline Item9 & 5. 760 & 1. 340 & 2.159 & 0.733 \\
\hline Item10 & 4. 707 & 1.637 & 2.592 & 0.571 \\
\hline Self-mastery-derived & 30.044 & 6.663 & & \\
\hline Means/process-or iented-derived & 21.754 & 4. 323 & & \\
\hline Total scale score & 51.798 & 9.985 & & \\
\hline \multicolumn{5}{|l|}{ SOPI } \\
\hline Item1 & 2. 950 & 1. 183 & 2.220 & 0.865 \\
\hline Item2 & 2. 928 & 1. 157 & 2.196 & 0.879 \\
\hline Item3 & 2. 871 & 1. 219 & 2.232 & 0.883 \\
\hline Item4 & 2. 712 & 1. 265 & 2.250 & 0.894 \\
\hline Item5 & 2. 688 & 1. 238 & 2.237 & 0.910 \\
\hline Item6 & 2. 647 & 1. 268 & 2.245 & 0.918 \\
\hline Item7 & 3. 208 & 1. 217 & 2.210 & 0.818 \\
\hline Item8 & 3. 082 & 1. 155 & 2.192 & 0.900 \\
\hline Item 9 & 3. 072 & 1. 233 & 2.257 & 0.860 \\
\hline Leisure & 8. 763 & 3. 360 & & \\
\hline Productivity & 8. 054 & 3. 670 & & \\
\hline Self-care & 9.362 & 3. 461 & & \\
\hline Summary score & 47. 782 & 25.666 & & \\
\hline \multicolumn{5}{|l|}{ K-1 Scale } \\
\hline Item1 & 1. 354 & 0.821 & 1.408 & 0.587 \\
\hline Item2 & 1. 173 & 0.833 & 1.377 & 0.738 \\
\hline
\end{tabular}




\begin{tabular}{lllll} 
Item3 & 1.421 & 0.764 & 1.275 & 0.689 \\
Item4 & 1.365 & 0.808 & 1.524 & 0.666 \\
Item5 & 1.482 & 0.773 & 1.556 & 0.683 \\
Item6 & 1.231 & 0.810 & 1.420 & 0.656 \\
Item7 & 1.159 & 0.819 & 1.542 & 0.713 \\
Item8 & 1.329 & 0.689 & 1.362 & 0.611 \\
Item9 & 1.397 & 0.786 & 1.281 & 0.707 \\
Item10 & 1.195 & 0.788 & 1.577 & 0.734 \\
Item11 & 1.441 & 0.701 & 1.542 & 0.744 \\
Item12 & 1.516 & 0.753 & 1.554 & 0.702 \\
Item13 & 1.504 & 0.733 & 1.544 & 0.588 \\
Item14 & 1.068 & 0.798 & 1.410 & 0.566 \\
Item15 & 1.187 & 0.824 & 1.392 & 0.607 \\
Item16 & 1.168 & 0.798 & 1.237 & 0.356 \\
Self-realization and will & 7.785 & 3.396 & & \\
Sense of Iife fulfilIment & 6.797 & 2.612 & & \\
Will to Iive & 2.950 & 1.237 & & \\
Sense of existence & 3.538 & 1.983 & & \\
Total scale score & 21.171 & 7.335 & & \\
\hline
\end{tabular}

1 
3

CFA of SOPI

$\mathrm{CFI}=0.982, \mathrm{TLI}=0.976, \mathrm{RMSEA}=0.058,90 \% \mathrm{Cl}[0.034,0.082]$.

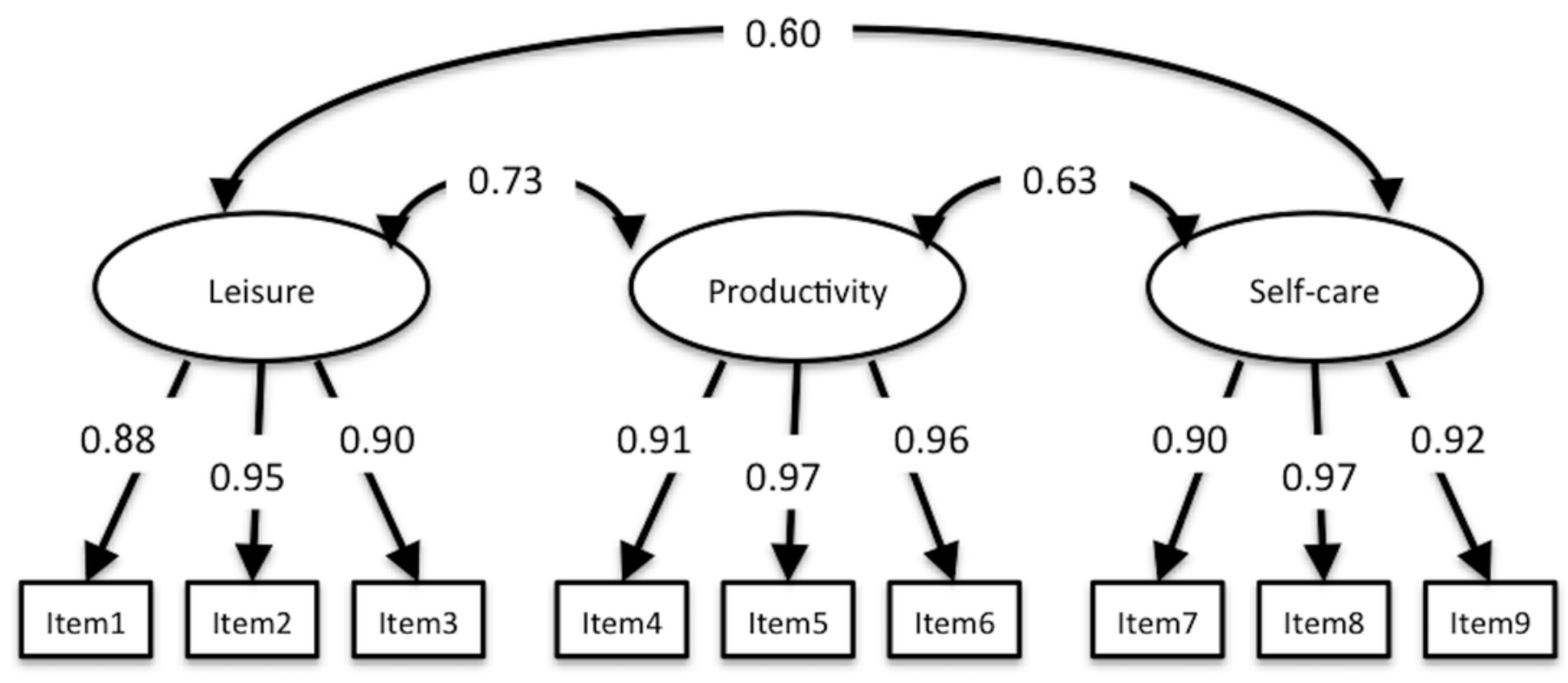




\section{Table 3 (on next page)}

Correlation between SAMR, SOPI, and K-1 Scale

Mastery = Self-mastery-derived; Means = Means/process-oriented-derived; SA Total = total scale score of SAMR; Product = Productivity; Summary = summary score of SOPI; Realize = Self-realization and will; Fulfill = Sense of life fulfillment; Will = Will to live; Exist $=$ Sense of existence; K-1 Total = total scale score of K-1 Scale. The values calculated by spearman correlation are on double line, the values calculated by polyserial correlation are on underline, and other values are calculated by polychoric correlation. ${ }^{*} p<.05$. ${ }^{* *} p<.01$. 
1

\begin{tabular}{|c|c|c|c|c|c|c|c|c|c|c|c|c|c|c|}
\hline \multirow[b]{2}{*}{ Leisure } & \multicolumn{2}{|c|}{ Mastery } & \multicolumn{2}{|c|}{ Means } & \multicolumn{2}{|c|}{ SA Total } & \multicolumn{2}{|c|}{ Leisure } & \multicolumn{2}{|c|}{ Product } & \multicolumn{2}{|c|}{ Self-care } & \multicolumn{2}{|c|}{ Summary } \\
\hline & $\underline{0.388}$ & $* *$ & $\underline{0.192}$ & ** & $\underline{0.337}$ & $* *$ & & & & & & & & \\
\hline Product & $\underline{0.420}$ & $* *$ & $\underline{0.217}$ & ** & $\underline{0.368}$ & $* *$ & & & & & & & & \\
\hline Self-care & $\underline{0.374}$ & $* *$ & $\underline{0.252}$ & ** & $\underline{0.353}$ & $* *$ & & & & & & & & \\
\hline Summary & $\underline{\underline{0.419}}$ & $* *$ & $\underline{\underline{0.237}}$ & ** & $\underline{\underline{0.377}}$ & $* *$ & & & & & & & & \\
\hline Realize & $\underline{0.542}$ & ** & $\underline{0.302}$ & ** & $\underline{0.494}$ & $* *$ & 0.326 & ** & 0.291 & $* *$ & 0.279 & ** & $\underline{0.323}$ & ** \\
\hline Fulfill & $\underline{0.347}$ & ** & $\underline{0.091}$ & & $\underline{0.271}$ & $* *$ & 0.291 & ** & 0.253 & $* *$ & 0.309 & ** & $\underline{0.308}$ & ** \\
\hline Will & $\underline{0.401}$ & ** & $\underline{0.253}$ & ** & $\underline{0.379}$ & ** & 0.286 & ** & 0.223 & ** & 0.161 & * & $\underline{0.246}$ & ** \\
\hline Exist & $\underline{0.404}$ & ** & $\underline{0.288}$ & ** & $\underline{0.407}$ & ** & 0.281 & ** & 0.306 & $* *$ & 0.310 & ** & $\underline{0.324}$ & $* *$ \\
\hline $\mathrm{K}-1$ Total & $\underline{\underline{0.534}}$ & $* *$ & $\underline{\underline{0.290}}$ & ** & $\underline{\underline{0.483}}$ & ** & $\underline{0.348}$ & $* *$ & $\underline{0.319}$ & $* *$ & $\underline{0.323}$ & ** & $\underline{\underline{0.362}}$ & ** \\
\hline
\end{tabular}


4

CFA of K-1 Scale

$\mathrm{CFI}=0.944, \mathrm{TLI}=0.932, \mathrm{RMSEA}=0.078,90 \% \mathrm{Cl}[0.066,0.089]$. Abbreviations of the four factors are similar to Table 3.

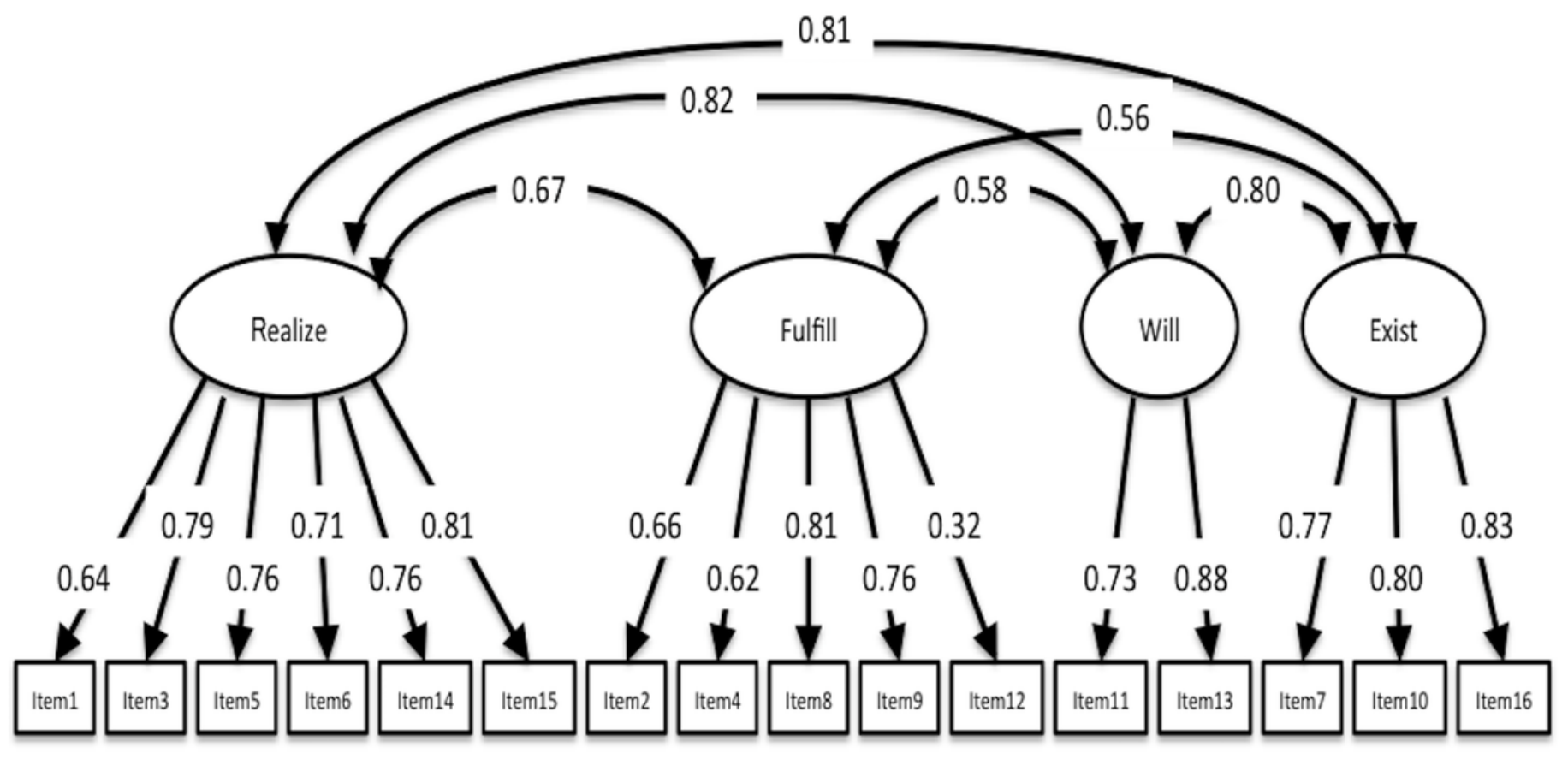




\section{Table 4(on next page)}

Correlation between SAMR, SOPI, K-1 Scale, and role expectation

Most of abbreviations are similar to Table 3. Total roles = total number of roles; Family = Family member; Hobbyist $=$ Hobbyist or Amateur; Organization $=$ Participant in organization . The values calculated by polyserial correlation are on underline, and other values are calculated by polychoric correlation. ${ }^{+} p<.10{ }^{*} p<.05$. ${ }^{* *} p<.01$. 


\begin{tabular}{|c|c|c|c|c|c|c|c|c|c|c|c|c|c|c|c|c|c|c|c|c|c|c|c|c|}
\hline & \multicolumn{2}{|c|}{ Mastery } & \multicolumn{2}{|c|}{ Means } & \multicolumn{2}{|c|}{ SA Total } & \multicolumn{2}{|c|}{ Leisure } & \multicolumn{2}{|c|}{ Product } & \multicolumn{2}{|c|}{ Self-care } & \multicolumn{2}{|c|}{ Summary } & \multicolumn{2}{|c|}{ Realize } & \multicolumn{2}{|c|}{ Fulfill } & \multicolumn{2}{|l|}{ Will } & \multicolumn{2}{|c|}{ Exist } & \multicolumn{2}{|c|}{ K-1 Total } \\
\hline Total roles & $\underline{0.314}$ & $* *$ & $\underline{0.199}$ & $* *$ & $\underline{0.298}$ & $* *$ & 0.287 & $* *$ & 0.272 & $* *$ & 0.281 & $* *$ & $\underline{0.305}$ & $* *$ & 0.443 & $* *$ & 0.284 & $* *$ & 0.216 & $* *$ & 0.364 & $* *$ & $\underline{0.414}$ & \\
\hline Volunteer & $\underline{0.217}$ & & $\underline{0.015}$ & & $\underline{0.150}$ & & 0.141 & & 0.064 & & 0.019 & & $\underline{0.090}$ & & 0.325 & $*$ & 0.371 & $*$ & - & & 0.198 & & $\underline{0.463}$ & + \\
\hline Care giver & $\underline{0.178}$ & & $\underline{0.320}$ & & $\underline{0.256}$ & & 0.097 & & 0.050 & & $\begin{array}{r}- \\
0.156\end{array}$ & & $\begin{array}{r}= \\
0.008\end{array}$ & & 0.345 & + & 0.362 & + & 0.161 & & 0.226 & & $\underline{0.324}$ & + \\
\hline House work & $\underline{0.023}$ & & $\underline{0.048}$ & & $\underline{0.051}$ & & 0.037 & & 0.126 & & 0.079 & & $\underline{0.087}$ & & 0.073 & & 0.022 & & $\begin{array}{r}- \\
0.100\end{array}$ & & 0.179 & $*$ & $\underline{0.056}$ & \\
\hline Friend & $\underline{0.313}$ & $* *$ & $\underline{0.154}$ & & $\underline{0.274}$ & $* *$ & 0.320 & $* *$ & 0.308 & ** & 0.372 & $* *$ & $\underline{0.372}$ & $* *$ & 0.452 & $* *$ & 0.231 & $*$ & 0.049 & & 0.257 & $* *$ & $\underline{0.405}$ & 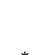 \\
\hline Family & $\underline{0.018}$ & & $\underline{0.013}$ & & $\begin{array}{r}= \\
\underline{0.004}\end{array}$ & & 0.050 & & 0.021 & & 0. & & $\underline{0.007}$ & & 0.050 & & 0.101 & & 0.290 & $* *$ & 0.080 & & $\underline{0.114}$ & \\
\hline Religionist & $\underline{0.355}$ & $*$ & $\underline{0.342}$ & & $\underline{0.396}$ & $*$ & 0.186 & & 0.011 & & 0.193 & & $\underline{0.139}$ & & 0.251 & + & 0.160 & & 0.186 & & 0.244 & & $\underline{0.271}$ & \\
\hline Hobbyist & $\underline{0.390}$ & $* *$ & $\underline{0.311}$ & $* *$ & $\underline{0.399}$ & $* *$ & 0.377 & $* *$ & 0.295 & $* *$ & 0.399 & $* *$ & $\underline{0.387}$ & $* *$ & 0.458 & ** & 0.303 & $* *$ & 0.131 & & 0.257 & $* *$ & $\underline{0.422}$ & * \\
\hline organization & $\underline{0.406}$ & $* *$ & $\underline{0.075}$ & & $\underline{0.294}$ & $* *$ & 0.275 & $*$ & 0.228 & + & 0.220 & + & $\underline{0.257}$ & + & 0.470 & $* *$ & 0.339 & $* *$ & 0.313 & $*$ & 0.427 & $* *$ & $\underline{0.522}$ & \\
\hline Worker & $\underline{0.079}$ & & $\underline{0.291}$ & & $\underline{0.176}$ & & 0.033 & & 0.194 & & 0.089 & & $\underline{0.111}$ & & 0.446 & $*$ & 0.403 & $*$ & 0.353 & & 0.528 & $* *$ & $\underline{0.534}$ & \\
\hline
\end{tabular}


5

Hypothesized model using SEM

$\mathrm{CFI}=0.986, \mathrm{TLI}=0.985, \mathrm{RMSEA}=0.047,90 \% \mathrm{Cl}[0.042,0.053]$. Most of abbreviations are similar to Table 3. Role Expectation $=$ total number of roles; $\mathrm{SA}_{-}=$items of SAMR; $\mathrm{SO}_{-}=$ items of SOPI; KS $=$ items of $\mathrm{K}-1$ Scale. The error terms are omitted to make the figure simple.

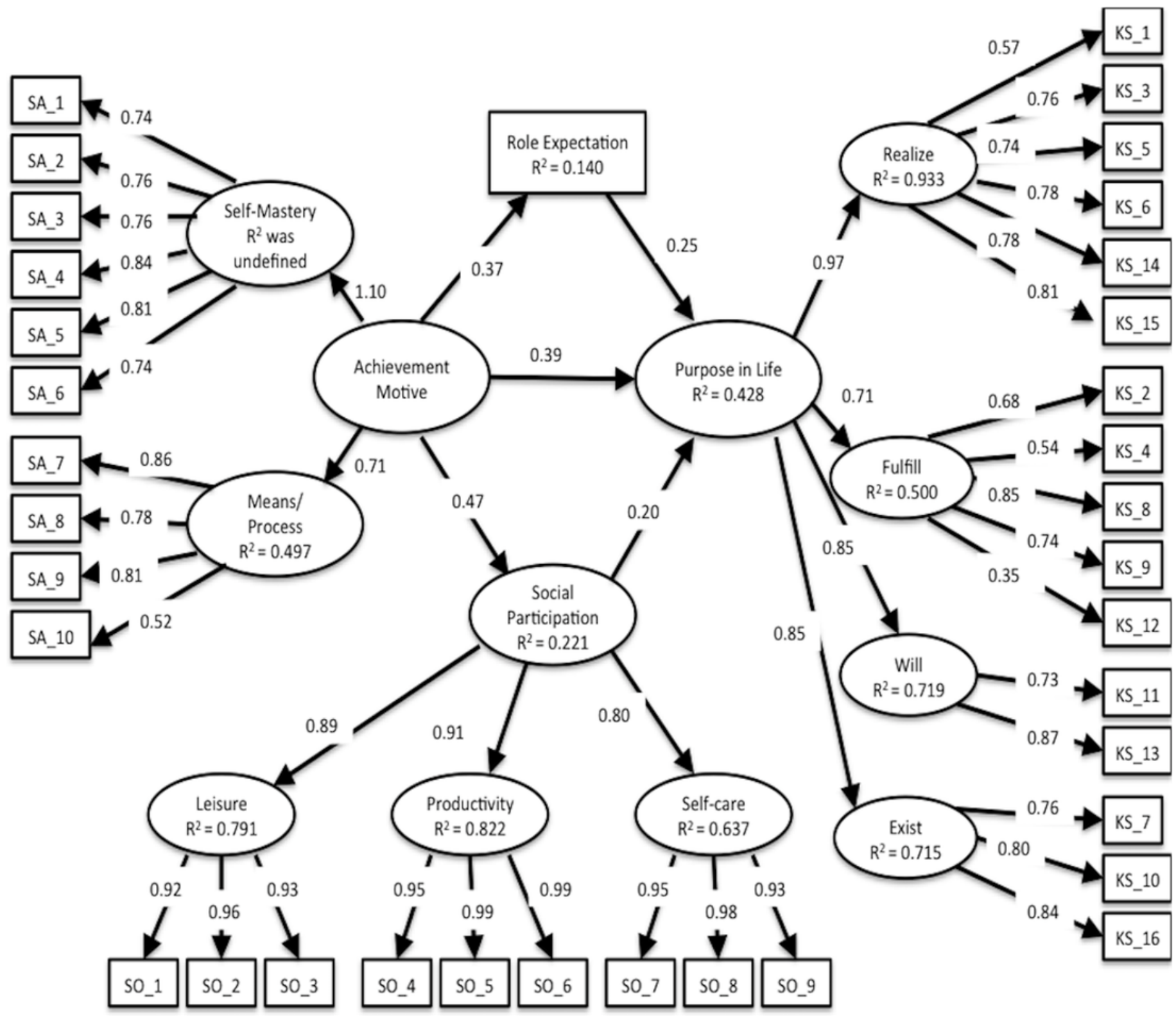


6

Modified model using SEM

$\mathrm{CFI}=0.984, \mathrm{TLI}=0.983, \mathrm{RMSEA}=0.050,90 \% \mathrm{Cl}[0.044,0.055]$. Abbreviations are similar to

Table 3 and Figure 5. Standardized path coefficients of Self-mastery-derived on the factor's items and achievement motive on two factors of SAMR were restricted to 1 . The error terms are omitted to make the figure simple.

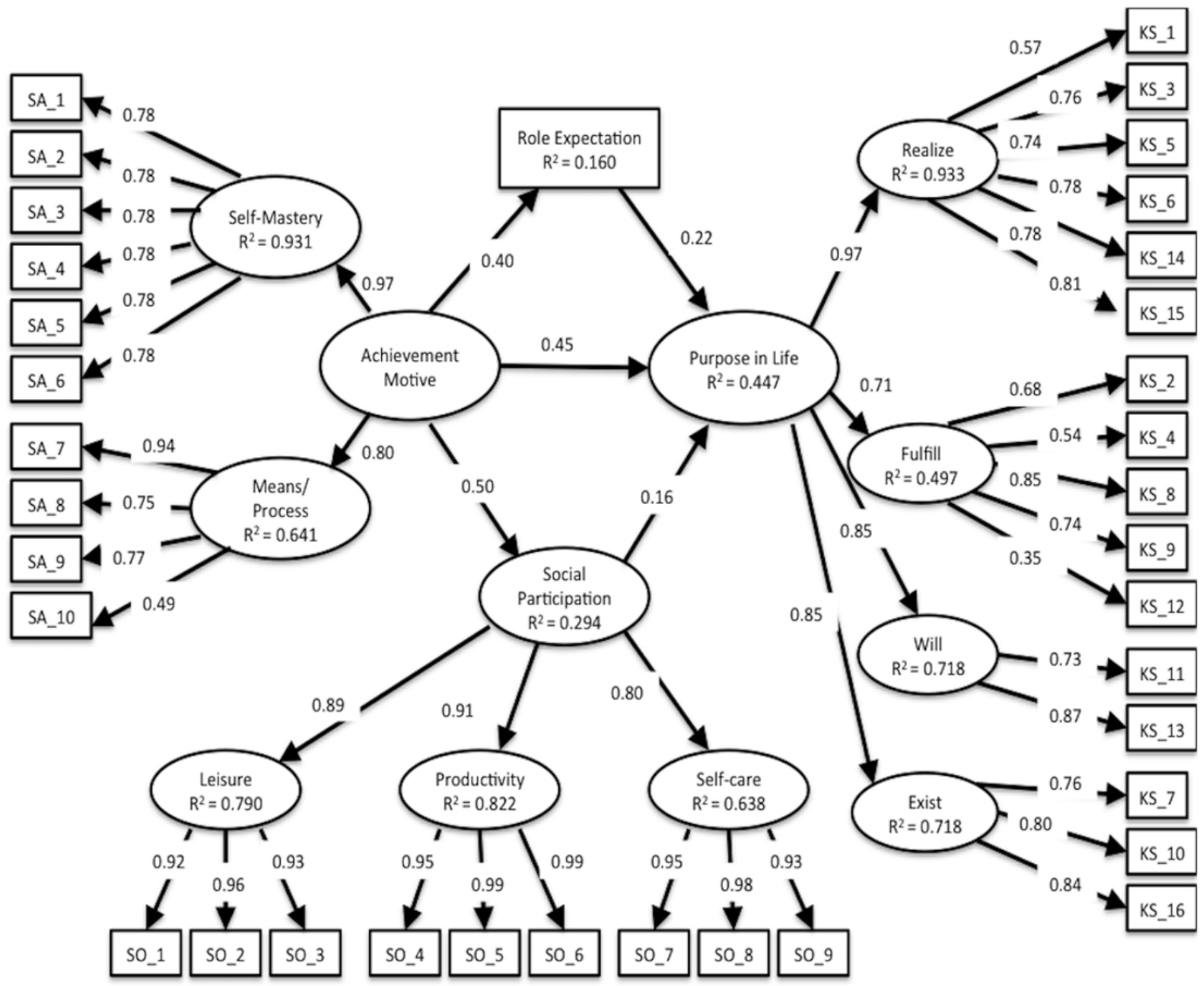

